\title{
How to Improve Foreign Language Teachers' Application Abilities of Information Technology in Big Data Era
}

\author{
Ge Liu $^{1, a}$ and Yandong Qu ${ }^{2, b}$ \\ ${ }^{1}$ Bohai University, Jinzhou 121003, China; \\ ${ }^{2}$ Liaoning University of Technology, Jinzhou 121001, China. \\ alg781115@163.com, bplxfeng2009@sohu.com
}

Keywords: Big Data era, foreign language teachers, information technology, application ability.

\begin{abstract}
The popularity of Internet and mobile terminals marks a new era of big data. The big data has increasingly been promoted as a revolutionary development in the future of science and technology. Application of information technology (IT) has been one of the necessary professional abilities of modern foreign language teachers in the big data era. How to improve foreign language teachers' application abilities of IT in the big data era has been one of research focus of foreign language teaching reform. Firstly, combining the properties of foreign language learning and learners' needs, the opportunities and challenges of foreign language teachers are analyzed in the present study. Secondly, the application abilities of modern IT for foreign language teachers are grouped into two levels: general application abilities and special application abilities. Finally, some measures are suggested to improve foreign language teachers’ application abilities of IT.
\end{abstract}

\section{Introduction}

With the rapid development and popularization of network technology and computer technology in the last decade, modern information technology (IT) has ushered in an era of big data, which brings with it new challenges as well as opportunities [1]. Big data is a buzzword, or catch-phrase, meaning that the existence of a massive volume of both structured and unstructured data sets from a variety of sources such as text, images, videos and audio [2]. People are getting used to web-based activities such as shopping online, reading, writing, reviewing and communicating online in the big data era. It is changing our way of thinking, mode of production and lifestyle, and arouses a new round of industrial and technological revolution. Web-based activities have been the part of our life, naturally changing the way of our learning for the acquisition of information and knowledge is no longer restricted by time and space[3]. Big data usually includes data sets with sizes beyond the ability of commonly used software tools to capture, curate, manage, and process data within a tolerable elapsed time [4]. In-depth integration of big data with various industries will exert unprecedented social and commercial value, play an important role in the social and economic development and bring more well-being to the human race. Big data requires a set of techniques and technologies with new forms of integration to reveal insights from datasets that are diverse, complex, and of a massive scale [3].

Since its birth, the applications of IT have been recognized in the field of foreign language teaching. Technological innovations is accepted to increase interest and motivation of learners, to provide students with increased access to target language input, interaction opportunities, and feedback; and to provide instructors with an efficient means for organizing course content and interacting with multiple students. Moreover, the use of new technology is criticized for it can give rise to inappropriate input, shallow interaction, and inaccurate feedback; student frustration with software and hardware; distraction from the learning task; and a general over-emphasis on delivery modality over learning objectives [4]. Therefore, it is necessary to study on how to make full use of IT in foreign language teaching and to avoid the deficiencies it may bring [4]. Applications of IT have been one of necessary professional abilities of modern foreign language teachers in the big data era. Firstly, combining the properties of language learning and learners' needs, the opportunities and challenges of foreign language teachers are analyzed in the present study. Secondly, the applications 
of modern IT for foreign language teachers are grouped into two levels: general ability and special ability. Finally, some measures are also suggested to improve foreign language teachers' application abilities of IT in big data era.

\section{Opportunities and Challenges of Foreign Language Teachers}

IT has a revolutionary impact on the development of education. It is necessary to strengthen the applications of IT to improve the teaching level of foreign language teachers, and thus improve the teaching effect [5]. Exploring the methods to use IT to promote foreign language teaching has been one of research focus of foreign language teaching reform. For example, Chen [6] discussed the relationship between Big Data and MOOCs, and he pointed out that big data, as the trend of human development, has triggered the emergence of MOOCs, thereby constituting some challenges to and opportunities for the foreign language teaching in China. On the basis of detailed data of the concept, characteristics, in-depth analysis of the data to foreign language teaching brings opportunities and challenge. Therefore, applications ability of IT should be included in the overall capability of modern foreign language teachers. In order to meet the big data era of development needs and trends, foreign language teachers should change the traditional teaching concepts, and learn how to use IT to promote foreign language teaching. According to Pennington, IT has the potential for enhancing foreign language learning by the unique properties and variety of the input that are made available by electronic resources such as CD-ROM, networks, and specific hardware and software [7]. Meanwhile, IT also brings challenges of foreign language teaching. The challenges include analysis, capture, search, sharing, storage, transfer, visualization, and information privacy [8]. The trend to larger data sets is due to the additional information derivable from analysis of a single large set of related data, as compared to separate smaller sets with the same total amount of data, allowing correlations to be found to "spot business trends, prevent diseases, combat crime, and so on"[9].

In conclusion, foreign language teachers should engage in collaborative interactions and actively seek various approaches to improve their application abilities of IT. Big data has brought many opportunities and challenges for foreign language teachers.

\section{Foreign Language Teachers’ Application Abilities of IT}

Since the birth of big data, computer applications have become indispensable work skills in people's lives. Foreign language teachers should have the ability to apply modern IT in the foreign language teaching process , in addition to the necessary language skills. The imbalance with teachers age, work areas, computer hardware and software, input time, and teacher training, could result in uneven of foreign language teachers' application abilities of IT. In the present study, foreign language teachers' application abilities of IT are grouped into two levels: general application abilities and special application abilities.

\section{(1) General application abilities}

In the stage of computer assisted instruction (CAI), most of foreign language teachers more or less have the following general application abilities of IT:

(a) Word document processing;

(b) Excel table and data processing;

(c) Image processing and making PPT files;

(d) Storing information;

(e) Audio processing;

(f) Video processing.

Foreign language teachers could more or less apply the general application abilities of IT mentioned above to produce courseware (PPT) and introduce them to classroom teaching directly. It has improved the teaching effect of foreign language. The computer IT and network technology have developed and improved under the background of the era of big data, however. Traditional foreign language teaching is fundamentally changing with the development of modern IT. The role of 
computer has gradually been one of the important factors in the foreign language teaching. It has not made full use of modern IT in China. Most of institutions have almost no relevant courses in the construction of database, however. Foreign languages teachers are required to have the general application abilities of IT. Moreover, modern foreign language teachers should have the following special abilities of IT to achieve better teaching effect.

\section{(2) Special application abilities}

The integration of IT and curriculum of foreign language is the research direction of college foreign language reform. An ideal learning environment and new learning methods could be created by IT. It should be emphasized that IT is the promotion tool of students' autonomous learning knowledge and emotional motivation. It is an indispensable part of foreign language teaching process. Therefore, foreign language teachers should not regard IT as an auxiliary teaching tools, but as an important participant in the teaching process. Meanwhile, for the foreign language teachers, the more the IT application abilities they have, the more easily grasp foreign language teaching in class. It is more easy for them to develop more suitable for students' needs three-dimensional foreign language teaching resources of network. These special abilities are more helpful for foreign language teachers to combine modern IT with foreign language teaching organically and harmoniously, and to achieve better teaching results.

\section{Measures to Improve Foreign Language Teachers’ Application Abilities of IT}

\section{(1) Establishing consciousness to improve application abilities of IT}

The development of IT has put forward higher requirements for foreign language teaching in the big data era. Moreover, it also brings great challenges to the professional development of foreign language teachers. In the network environments, students' knowledge structures and concept system are constantly changing. Foreign language teachers should renew their educational ideas, timely adjust the students' outlook and teaching outlook in foreign language teaching process. Facing the rapid development of IT, foreign language teachers should have the initiative to establish the consciousness to improve the application abilities of IT in the foreign language teaching process.

\section{(2) Mutual assistance training}

In order to explore and solve the problems encountered in the teaching process of technical problems you can learn from your colleagues with strong application abilities of IT. As far as foreign language teachers is concerned, they have very similar professional background and teaching difficulties. When encountering more difficult technical problems, you can learn IT from the professional teachers in your college. It is more convenient to improve application abilities of IT of foreign language teachers by mutual assistance training.

\section{(3) Broaden the horizons of foreign language teachers}

Facing the rapid development of computer science and technology, foreign language teachers want to obtain the latest technology in the foreign language teaching process. Therefore, They should consciously cultivate the self-study abilities of college students in the teaching process, and they are proficient in using Internet to obtain the latest IT knowledge. Computer assisted instruction (CAI) is universal used at home and abroad. It has good man-machine conversation function and overcome the less teachers students. CAI has good animation effects, especially for boring concept. Therefore, a large number of similar auxiliary teaching software should be introduced in the foreign language teaching process.

\section{(4) Grading training}

It is urgent to cultivate and improve modern foreign language teacher's ability of applying IT. The technical problems encountered by foreign language teachers are also different due to the unbalanced development of modern IT. Therefore, the grading training can be helpful for foreign language teachers with different application abilities of IT.

\section{(5) Participating in contest of informatization teaching}

Foreign language teachers could participate in all kinds of contest of informatization teaching. The teachers with different professional back grounds, will make their own courseware with leading 
technology, and novel design. Contest of informatization teaching could provide foreign language teachers the environment with learning and training, consultations and communication.

\section{(6) Attending seminars of foreign language teaching}

Foreign language teachers should always strive for the opportunity to attending seminars of foreign language teaching. These workshops could provide a platform for mutual exchange, improvement and cooperation. Attending such seminars, foreign language teachers can broaden their horizons, get to know more from the mentor, and enhance their IT skills. They can explore new technology and promote technological development of foreign language teaching.

\section{Conclusions}

The popularity of Internet and mobile terminals marks a new era of big data. Applications of IT have been one of the necessary professional abilities of modern foreign language teachers. Application abilities of modern IT in the foreign language teaching process are grouped into two levels: general application abilities and special application abilities. When IT is applied in foreign language teaching process, the success or failure of teaching mainly depends on the design of teaching plans. Foreign language teachers are confronted with new challenges in the big data. They should come out from the traditional understanding and practice of professional survival, roles and responsibilities, to accept the background of the era of big data, and the baptism of the new teaching concept.

\section{Acknowledgement}

The authors acknowledge financial support from Social Science Foundation of Liaoning Province in China (grand no. L15AWW002).

\section{References:}

[1] J. Hong. An application-aware approach to systems support for big data. IEEE, International conference on application-specific systems, architectures and processors IEEE computer society, 2013:1-1.

[2] I. Ritola. Exploring the concept of big data: technologies, solutions and best practices. Lapin Ammattikorkeakoulu, 2014.

[3] J. H. Fan. On information technology and foreign language teaching in big data era [C] The 2nd, information technology and mechatronics engineering conference. 2016.

[4] V. Chavan, N. P. Rajesh. Survey paper on big data. International journal of computer science and information technologies. 5(2014)7932-7939.

[5] State planning outline for medium and long-term education reform and development (20102020). http://www.gov.cn/jrzg/2010-07/29/content_1667143.htm.

[6] J. L. Chen. MOOCs and foreign language teaching studies in the big data era-challenges and opportunities. Technology enhanced foreign language education, 2015.

[7] M.C. Pennington. Cycles of innovation in the adoption of information technology: a view for language teaching. Computer assisted language learning.17(2004)7-33.

[8] V. Govindaraju, V. Raghavan and C. R. Rao. Handbook of statistics, big data analytics, volume 33(1st Edition).2015.

[9] Big data. https://en.wikipedia.org/wiki/Big_data. 